\begin{tabular}{l}
\hline Nuansa Journal of Arts and Design \\
Volume 4 Nomor 2 September 2020 \\
e-ISSN: $2597-405 X$ dan p-ISSN: $2597-4041$ \\
\begin{tabular}{|l|l|} 
@) (1) This work is licensed under a Creative Commons Attribution \\
\hline
\end{tabular} 4.0 International License
\end{tabular}

\title{
Implementasi Blended Learning dalam Pendidikan Seni di Era New Normal
}

\section{Muhajir $^{1}$ Damar Tri Afrianto ${ }^{2}$}

\author{
Corespondensi Author ${ }^{1}$ \\ Program Studi Desain Grafis \\ Politeknik Negeri Media Kreatif \\ PSDKU Makassar \\ Email: \\ muhajir@polimedia.ac.id
}

\section{Corespondensi Author ${ }^{2}$}

Fakultas Seni Rupa Dan Desain, Institut Seni dan Budaya

Sulawesi Selatan, Kota Makassar

Email:

damar.tri.a@gmail.com

\begin{abstract}
ABSTRAK
Penelitian ini didasarkan sebuah permaslahan bahwa metode Blended Learning bukan menjadi solusi utama pembelajaran pendidikan seni di tingkat dasar hingga perguruan tinggi. Permasalahannya diantaranya yaitu kesenjangan yang menjadi isu sentral dalam pembelajaran via daring ini. Masih banyak daerah-daerah yang belum mendapat akses internet dan ketersedian perangkat teknologi (komputer dan gawai) sebagai modal utama pembelajaran daring. Di sisi lain, metode blended leraning tidak bisa sepenuhnya diterapkan secara total dalam pendidikan seni. Dari permasalahan tersebut perlu kiranya perlu merumuskan ulang metode pembelajaran seni di era tatanan baru ini, pembelajaran seni tak cukup hanya mengandalkan sistem daring, karena olah rasa, olah teknis dan estetika sebagai perangkat utama pendidikan seni, membutuhkan proses pendampingan yang intens. Masalah utama yang menjadi fokus pembahasan adalah bagaimana metode penunjang Blended Learning agar dapat dimplementasikan dalam pendidikan seni. Metode penelitian ini adalah penggabungan penelitian Research and Development (R \& D) dengan interpretatif analitik. Penelitian R\&D adalah jenis yang berangkat dari kasus kemudian manawarkan solusi untuk pengembangan. Hasil penelitian ini merumuskan sistem Blended Learning dalam pembelajaran seni perlu ditunjang setidak-tidaknya dengan metode kolaborasi dengan stakeholder. Stakeholder inilah yang memiliki peran penting dalam asupan keilmuan teknis melalui pengalaman mereka di dunia kesenimanan. Guru dan dosen pengampu utama akan berkoordinasi dengan stakeholder tentang bagaimana proses berkarya peserta didiknya, sehingga kolaborasi ini mampu memberi warna pendidikan seni semakin variatif dan humanitif.
\end{abstract}

Kata Kunci: Blended Learning, Pendidikan Seni, Metode Kolabarosi Stakeholder 


\author{
Muhajir \\ Damar Tri Afrianto \\ Implementasi Blended Learning dalam Pendidikan Seni di Era New Normal
}

\title{
ABSTRACT
}

This research is based on a problem that the Blended Learning method is not the main solution for learning art education at the elementary to tertiary level. The problems include the gap that is a central issue in online learning. There are still many areas that do not yet have internet access and the availability of technological devices (computers and devices) as the main capital of online learning. On the other hand, the blended leraning method cannot be totally applied in art education. From these problems it is necessary to reformulate the methods of art learning in this new order era, learning of arts is not enough to rely solely on online systems, because if taste, technical processing and aesthetics as the main tools of art education, requires an intense mentoring process. The main problem that is the focus of the discussion is how the supporting methods of Blended Learning can be implemented in art education. This research method is a merging of Research and Development $(R \& D)$ research with interpretive analytics. $R \& D$ research is the type that departs from the case then offers solutions for development. The results of this study formulate a Blended Learning system in learning arts that need to be supported at least by a method of collaboration with stakeholders. These stakeholders have an important role in the intake of technical knowledge through their experience in the artistic world. The main teacher and lecturer will coordinate with the stakeholders on how the students' creative process works, so that this collaboration is able to give color to an increasingly varied and humanitive art education.

Key Word: Blended Learning method, art education, method of collaboration with stakeholders

\section{PENDAHULUAN}

Memasuki era kenormalan baru atau populer dangan jargon New Normal menjadi momentum besar bagi insan pendidikan untuk merefleksikan diri. Pasalnya gelombang Covid-19 selema lebih dari dua bulan telah mengahantam infrastuktur pendidikan secara masif. Selama pandemic pendidikan kita menjalani interaksi sosial baru yaitu pendidikan dalam jaringan (daring). Hal ini sejalan dengan instruksi dari Kementerian Pendidikan dan Kebudayaaan, semua sistem pendidikan bertumpu pada sistem jaringan dengan segala perangkat yang mendukungnya. Di saat semua jarak dibatasi baik melalui social distancing maupun Physical Distancing, komunikasi jejaring internet menjadi aspek dominan ketika keterisoliasian manusia untuk pencegahan merebaknya wabah Covid-19. Sebagai konsekuensi logis, ruang kelas-kelas 
itu telah bermigrasi dari ruang sosial langsung menjadi ruang sosial virtual. Pendidikan kita yang selalu menggantungkan pada aspek formal, seperti ruang kelas, interaksi, dan administrasi harus menghadapi kenyataan hilangnya aspek-aspek tersebut.

Pendidikan di Indonesia sepertinya masih belum mengoptimalkan efek dari pendidikan virtual atau daring yang berlangsung selama pandemi ini. Yang terjadi hanya sekedar berpindah ruang, 'dari kelas menjadi di rumah', metode pembelajaran tidak ada perubahan bahkan dikatakan sama. Saat pendidikan daring atau online dijalankan jutru memberi kesempatan insan pendidikan untuk terhubung secara luas dan global mengingat jejaring internet memberi akses konektivitas pengetahuan tak terbatas, namun barangkali itu belum terjadi karena kredo-kredo dogmatik masih berlangsung.

Di sisi lain, kita temui permasalahan tentang kesenjangan yang menjadi isu sentral dalam pembelajaran via daring ini. Masih banyak daerah-daerah yang belum mendapat akses internet dan ketersedian perangkat teknologi (komputer dan gawai) sebagai modal utama pembelajaran daring. Harian Kompas (28/6/2020) mewartakan kepemilikikan komputer di tingkat rumah tangga hanya 20,05 persen, penetrasi internet baru 66,22 persen serta tingginya harga paket sambungan internet menjadi beberapa hambatan. Pada akhirnya pembelajaran daring pun justru berpotensi memperluas kesenjangan sosial, karena pembelajaran daring ini hanya bisa diikuti oleh mereka yang mempunyai akses ke sumber daya digital.

Begitu juga pendidikan dalam bidang seni, pembelajaran seni di tingkat dasar hingga perguruan tinggi terdampak paling signifikan. Pembelajaran seni pada tingkat dasar, pertama dan menengah, kehadiran guru seni sebagai percontohan dan pemberi materi teknis hilang seketika dan berpindah ke layar-layar gawai. Mereka tentu akan kehilangan sosok guru yang menjadi pandu untuk menemani mereka berproses dalam menciptakan karya seni. Begitu juga dengan Pendidikan Seni di tingkat perguruan tinggi, semua akses sajian seni dari mulai pemeran seni rupa dan desain, festival musik, pertunjukan teater, tari dan sejumlah pagelaran seni yang lain di tutup. Aktifitas seni di ruang publik tentu akan bertentangan dengan salah satu jargon populer selama pandemi yaitu "jaga jarak' dan "hindari keramaian"

Memasuki tatanan kenormalan baru, dunia pendidikan mencuatkan istilah Blended Learning atau sistem pembelajaran campuran. Sistem tersebut menerapkan kombinasi pengajaran langsung (face to face) dan pengajaran online (Sari, 2013: 34). Kombinasi itu tak lain sebagai adaptasi dunia pendidikan pasca pandemi, dan menutupi kekurangan dan hambatan sistem pembelajaran daring. Beberapa sekolah dan perguruan tinggi telah menerapkan sistem Blended Learning tersebut. Di bidang ilmu seni, sekolah dan perguruan tinggi yang menyediakan program dan pembelajaran seni, metode Blended Learning tidak dapat sepenuhnya menjadi solusi, perlu adannya upaya penunjang dan integrasi dalam penerapan Blended learning tersebut.

Dari permasalahan tersebut perlu kiranya merumuskan ulang metode pembejaran seni di era tatanan baru ini, pemebelajaran seni tak cukup hanya mengandalkan sistem daring, karena olah rasa, olah teknis dan estetika sebagai perangkat utama pendidikan seni membutuhkan proses pendampingan yang intens. Masalah utama yang menjadi fokus pembahasan adalah bagaimana metode penunjang Blended Learning agar dapat dimplementasikan dalam pendidikan seni. Adapun tujuannaya agar 1) elaborasi blended Learning dapat menjadi pandu pendiddikan seni dalam mengimplementasikan pembelajaran dengan tidak menghilangkan aspek olah rasa, teknis, dan estetika, 2) pembejaran Seni tidak hanya menggantungkan pada teknologi daring (online). 
Muhajir

Damar Tri Afrianto

Implementasi Blended Learning dalam Pendidikan Seni di Era New Normal

\section{METODE}

Metode penelitian erat kaitannya dengan strategi untuk memahami realita sehingga penelitian mampu menghasilkan sesuatu yang relevan dengan tujuan penelitian. Langkah untuk mewujud tujuan penelitian tersebut diperlukan sebuah metode penelitian yang berisi cara-cara, strategistrategi dan langkah-langkah sistematis. Tjetjep Rohendi Rohidi menjelasakan metode penelitian yaitu suatu cara untuk bergerak atau melakukan sesuatu secara sistematis dan tertata, keteraturan pemikiran dan tindakan, atu juga teknik dan susunan kerja dalam bidang atau lapangan tertentu (Rohidi, 2011: 171).

Metode penelitian ini adalah penggabungan penelitian Research and Development (R \& D) dengan interpretatif analitik. Penelitian R\&D adalah jenis yang berangkat dari kasus kemudian manawarkan solusi untuk pengembangan. Dalam penelitian $\mathrm{R} \& \mathrm{D}$ konsep yang diterapkan adalah Abductive, yatu penalaran yang memungkinkan terbentuknya hipotesa tertentu yang dilakukan mulai dari kasus khusus dengan eksplanasi yang mungkin tentang kasus tersebut (Rusdi, 2018). Dari konsep Abductive tersebut melalui hipotesa kasus kemudian diteruskan pada interpretasi analisis. Interpretasi adalah proses menafsir kenyataan dengan memberikan perspektif- perspektif pandangang dengan suatu kerangka paradigmati

Data-data dianalisis selanjutnya disajikan dalam bentuk deskripsi. Bogdan dan Taylor (Ratna 2010: 94), menjelaskan bahwa kualitatif adalah metode yang pada gilirannya menghasilkan data deskriptif dalam bentuk kata-kata, baik tertulis mapun lisan. Dalam hal ini penelitian kualitatif yang dilakukan tidak semata-mata mendeskripsikan tetapi yang lebih penting adalah menggambarkan, menjelaskan dan mengungkap realitas yang terjadi di lapangan.

\section{HASIL DAN PEMBAHASAN}

\section{Metode Blended Leraning}

Belum berakhirnya pandemi Covid19, pembejaran jarak jauh tetap akan menjadi opsi sebagian instansi pendidikan, baik sekolah maupun kampus. Pembelajaran di sekolah dan kampus pada masa normal baru pasti akan berbeda dengan pra pandemi. Metode baru untuk pendidikan yang lebih menjamin kualitas dan akses pendidikan yang setara menjadi kebutuhan saat ini.

Memasuki tatanan kenormalan baru, dunia pendidikan mencuatkan istilah kembali istilah Blended Learning atau sistem pembelajaran campuran. Sistem tersebut menerapkan kombinasi pengajaran langsung (face to face) dan pengajaran online (Sari, 2013: 34). Kombinasi itu tak lain sebagai adaptasi dunia pendidikan pasca pandemi, dan menutupi kekurangan dan hambatan sistem pembelajaran daring. Beberapa sekolah dan perguruan tinggi telah menerapkan sistem Blended Learning 
tersebut. Di bidang ilmu seni, sekolah dan perguruan tinggi yang menyediakan program dan pembelajaran seni, metode Blended Learning tidak dapat sepenuhnya menjadi solusi, perlu adannya upaya penunjang dan integrasi dalam penerapan Blended learning tersebut.

Blended Learning sebagai sebuah metode pembelajaran telah diterapkan sebelum pandemic Covid-19 mewabah. Metode ini lahir dari inovasi pembelaran dan pendidikan di era revolusi teknologi atau di era 4.0. Penggabungan yang dilakukan secara baik antara pengajaran tatap muka dimana pengajar dan pebelajar bertemu langsung dan melalui media online yang bisa diakses kapanpun (Wardani dkk, 2018: 14). Mobilitas manusia yang semakin padat dan lahirnya teknologi-teknologi baru, menjadi latar belakang lahirnya model pembelajaran blended learning sebagai inovasi baru dalam menjawab tantangan zaman. Blended learning adalah istilah dari pencampuran antara model pembelajaran konvensional yang biasa dilakukan secara face to face dengan model pembelajaran berbasis internet yang biasa dikenal dengan istilah e-learning (Purnomo, 2016: 71). Graham (dalam Sari, 2014: 127) menyebutkan definisi dari blended learning yang sering disampaikan adalah pembelajaran yang menggabungkan dengan media pembelajaran, pembelajaran yang menggabungkan model-model pembelajaran dan teori-teori pembelajaran, dan pembelajaran yang menggabungkan pembelajaran tatap muka (face-to-face) dengan pembelajaran online.

Blended Learning sebagai sebuah metode pembelejaran dapat dikatakan populer, karena penerapan teknologi menjadi penunjang kemudahan pembelajaran. Beberapa kelebihan dari blended learning yang diungkapkan oleh Kusairi (dalam Husamah 2014: 35), yaitu: a) peserta didik leluasa untuk mempelajari materi pelajaran secara mandiri dengan memanfaatkan materi materi yang tersedia secara online. b) peserta didik dapat berkomunikasi/ berdiskusi dengan pengajar atau peserta didik lain yang tidak harus dilakukan saat di kelas (tatap muka). c) kegiatan pembelajaran yang dilakukan peserta didik di luar jam tatap muka dapat dikelola dan dikontrol dengan baik oleh pengajar. d) pengajar dapat menambahkan materi pengayaan melalui fasilitas internet. e) pengajar dapat meminta peserta didik membaca materi atau mengerjakan tes yang dilakukan sebelum pembelajaran f) pengajar dapat menyelenggarakan kuis, memberikan balikan, dan memanfaatkan hasil tes dengan efektif. g) peserta didik dapat saling berbagi file dengan peserta didik lainnya.

Beberapa keunggulan dan manfaat posistif Blended Learning di atas tentunya tidak semua bidang ilmu bisa menerapkan tersebut. Pada bidang ilmu seni terutama, memiliki metode gaya pembelajaran yang identik dan otentik. Tentunya blended leraning harus disesuikan dengan gaya pembelajaran bidang studi masing-masing. Menurut Bobby De Porter \& Mike Hernacki (dalam Nikmawati, 2014: 24) gaya belajar dikelompokan menjadi 3, yaitu gaya belajar visual, gaya belajar audio dan gaya belajar kinestetik. Pembelajaran Seni menerapak tiga gaya belajar tersebut. Bidang studi yang menerpakan hanya gaya belajar audio dan visual barangkali akan berhasil dalam mengikuti pembelajaran dengan penerapan blended learning, akan tetapi untuk gaya belajar kinestetik mungkin memiliki kesempatan kecil akan berhasil pada proses pembelajaran. Kinestetik membutuhkan peretemuan lansgung, karena dalam seni proses pendampingan menjadi modal utama peserta didik mencapai karya seni yang berkualitas. Di sanalah terjadi transformasi ilmu dengan konsep 'rasa' antara pendidik dan peserta didik dengan keintiman yang tidak dapat digantikan pada layar gawai dan komputer. 


\section{Muhajir \\ Damar Tri Afrianto \\ Implementasi Blended Learning dalam Pendidikan Seni di Era New Normal}

\section{Metode Penunjang Blended Learning dalam Pembelajaran Seni}

Pendidikan seni terbilang paling kompleks dalam metode pembelajarannya. Di samping ketrampilan teknis, juga harus memiliki kepekaan logika rasa dan imajinasi. Oleh karenanya, seperti penjelasan di atas bahwa metode blended learning perlu dieksplorasi dan dikolaborasikan. Sistem Blended Learning dalam pembelajaran seni perlu ditunjang setidak-tidaknya dengan metode kolaborasi dengan stakeholder. Blended Learning pada aspek pembelajaran langsung, pengajar tidak hanya dari pengampu utama yaitu guru seni dan dosen. Sekolah dan perguruan tinggi dalam hal ini bisa menggandeng stakeholder yatu seniman, budayawan di beberapa daerah yang satu zonasi dengan tempat tinggal peserta didik. Peserta didik dapat berlajar langsung dengan seniman dan budayawan yang satu daerah.

\section{Metode kolaborasi dengan} stakeholder ini pernah menjadi program Kementerian Pendidikan Dan Kebudayaan melalui progam "Belajar Dengan Maestro" . Progam ini menjadi alternatif belajar di luar sekolah formal. Peserta program 'Belajar Dengan Maestro" mendapatkan pengalaman belajar dari maestro-maestro seni di Indonesia. Peserta didik diberi kesempatan untuk tinggal bersama dengan Maestro atau dengan masyarakat di lingkungan tempat tinggal Maestro. Konsep belajar demikian diharapkan mampu menginspirasi dan memotivasi para peserta didik, baik yang ingin menjadi penampil seni maupun tidak, untuk menghargai substansi seni dan merefleksikan diri mereka melalui proses berkesenian. Progam "belajar dengan Maestro' perlu kiranya ditumbuhkan kembali di saat pas pandemi ini. Sekolah atau kampus menjalin kerja sama dengan budayawan dan seniman mestro untuk pembelajaran di dearah masing-masing tentu dengan menggunkan protokol kesehatan. Progam belajar maestro sangat strategis dielborasi dengan metode blended learning. Peserta didik dapat berlajar langsung dengan seniman dan budayawan yang satu daerah, sehingga meminimalisir peserta didik untuk keluar dari daerahnya karena situasi pandemic. Di satu sisi medapatkan pengalaman belajar secara langsung oleh seniman dan budayawan setempat. Proses kreatif peserta didik dalam berkarya masih mendapatkan pendampingan secara intim lewat kehadiran seniman dan budayawan.

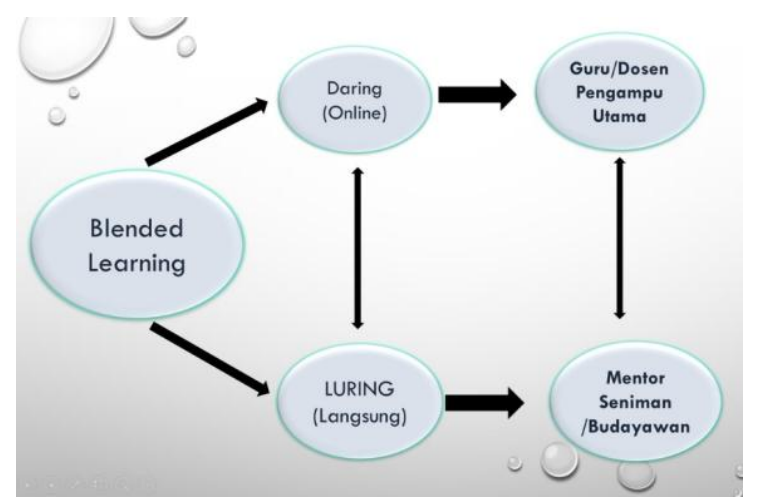

Bagan1. Metode Penunjang Blended Learning

Metode penunjang blended lerning ini adalah bentuk perubahan yang berupa eksplorasi blended learning pada umumnya. Hal ini sangat straegis dalam pembelajaran ilmu seni, karena mereka bisa berkarya dari rumah dan mendapatkan pengalaman belajar dari seniman dan budayawan setempat yang menemani mereka saat proses berkarya seni. Ilmu seni memang tak cukup hanya persoalan teori, namun kemampuan teknis haruslah dikuasai. Stakeholder inilah yang memiliki peran penting dalam asupan keilmuan teknis melalui pengalaman mereka di dunia kesenimanan. Guru dan dosen pengampu utama akan berkoordinasi dengan stakeholder tentang bagaimana proses berkarya peserta didiknya, sehingga kolaborasi ini mampu memberi warna pendidikan seni semakin variatif dan humanitif.

Stakeholder dalam bidang seni, baik seniman maupun budayawan bisa dikatakan turut menyumbang pendidikan di masa pasca pendemi. Pemrmaslahan Pendididikan seni 
yang otenik dan identitik dapat diakselarasi penyelesaiinya dengan kehadiran mentormentor dari seniman dan budayawan, mereka adalah 'pengalaman' sedangkan guru dan dosen adalah 'pengetahuan bagi peserta didik.

\section{PENUTUP}

Di titik ini media teknologi bukanlah solusi atas permasalahan pendidikan di Indonesisa terutama pendidikan seni. Di satu sisi, pemindahan pembelajaran fisik ke ruangruang virtual memang menjadi keniscayaan di tengah pandemi, teknologi virtual membantu secara periodik atau kedaruratan saat pandemi Covid-19, namun kita tidak bisa berharap banyak karena dunia digital menyebabkan kesenjangan sosial. Mereka yang mampu mengakses internet akan mendapatkan manfaat, sebaliknya yang tidak mampu mengakses mereka akan tertinggal. Ada indiksasi bahwa pendidikan melalui daring berpotensi penyeragaman (homogenesisasi) konten pembelajaran, tentu ini sangat bertolah belakang dengan pendidikan seni, yang mengutamakan sisi hetero dalam imajinasi, kreatifitas, dan inovasi.

Kembali hadirnya metode blended learning dalam situasi pasca pandemi atau new normal perlu kita tinjau ulang, bukan lantas kita serap mentah-mentah menjadi solusi utama. Perlu mempertimbangan karakter bidang studi terutama bidang ilmu seni. Ilmu seni adalah rumoun humaniora yang tidak bisa menyerahkan semua pada pendidikan daring atau online. Jangan sampai pendidikan seni larut dalam kemudahan teknologi, sehingga melalai kan tujuan utama pendidiikan ini yaitu menuju manusia yang kreatif dan humanis.

Oleh karena penting mengelaborasi metode blended Learning, dalam peneleitian ini merumuskan strategi yaitu metode kolaborasi dengan stakeholder. Kolabarasi ini mengajak seniman dan budayawan untuk menjadi guru atau dosen pendamping peserta didik. Seniman dan budayawan yang dipilih adalah yang memiliki kesamaan daerah tau berdekatan dengan tempat tinggal peserta didik. Mereka dapat belajar secara langsung dan mendapatkan ilmu dari seniman dan budaywan secara intim. Ini bisa diterapkan untuk penunjang blended learning pada bagian luring (luar jaringan). Peserta didik tetap bisa belajara di daerahnya masingmasing dan guru serta dosen bisa menjadi tempat mereka berkonsultasi melalui daring (online). Gagasan hasil penelitaian tersbut me njadi jawaban utama permasalahan bagaimana mengimplemetasikan blended learning dalam pendidikan seni

\section{DAFTAR PUSTAKA}

Husamah. (2014). Pembelajaran Bauran (Blended Learning) Terampil Memadukan Keunggulan Pembelajaran Face-To-Face, ELearning Offline-Online, Dan Mobile Learning. Jakarta: Prestasi Pustaka.

Miles, Matthew B. \& A. Michael Huberman. (1992). Analisis Data Kualitatif. Terj. Tjetjep Rohendi Rohidi.Jakarta:UniversitasIndonesia, UI Press.

Nikmawati, Ika Syukrun. 2014. "Korelasi Gaya Belajar Siswa Kelas VII dengan Hasil Belajar Mata Pelajaran Sejarah Kebudayaan Islam di Sekolah Menengah Pertama (SMP) Islam Durenan Trenggalek" . Skripsi, Fakultas Tarbiyah Dan Ilmu Keguruan, Pendidikan Agama Islam, IAIN Tulungagung

Purnomo, Agus. Nurul Ratnawati. Nevy Farista Aristin. 2016. "Pengembangan Pembelajaran Blended Learning Pada Generasi Z". Jurnal Teori dan Praksis Pembejaran IPS. Vol.1 (1). 70-77

Ratna, Nyoman Kutha. 2010. Metode Penelitian: Kajian Budaya dan Ilmu 


\section{Muhajir}

Damar Tri Afrianto

Implementasi Blended Learning dalam Pendidikan Seni di Era New Normal

Sosial Humaniora Pada Umumya.

Yogyakarta. Pustaka Pelajar.

Rohidi, Tjetjep Rohendi. (2012) Metode

Penelitian Seni. Semarang: Cipta Prima

Nusantara.

Rusdi, Muhammad . 2018. "Bahan Presentasi Workshop Pengembangan Media \& Sumber Belajar Berbasis R \& D” FKIP Universitas Riau: Pekanbaru,

Sari, Anita Ratna. 2013. "Strategi Blended Learning Untuk Peningkatan Kemandirian Belajar Dan Kemampuan Critical Thinking Mahasiswa Di Era Digital". Jurnal Pendidikan Akuntansi Indonesia. Vol. XI, No. 2 (hlm. 3243).

Sari, Milya. 2016. "Blended Learning, Model Pembelajaran Abad Ke-21 Di Perguruan Tinggi.Ta'dib". Jurnal Fakultas Pendidikan dan Pelatihan Guru, Universitas Batusangkar, Vol. 17(2), 126-136.

Wardani, Deklara Nanindya. Anselmus J.E. Toenlioe Agus Wedi. 2018. "Daya Tarik Pembelajaran Di Era 21 Dengan Blended Learning". Jurnal Kajian Teknologi Pendidikan. Vol.1 (1). 1318.

Yovita Arika.2020. "Semangat Gegas Reformasi Pendidikan". Dalam Harian Kompas 28 juni 2020. Jakarta 